\title{
Oral health status and performance of oral functions in children and adolescents in the treatment for overweight or obesity
}

\author{
Maria Ívina Gomes Janoca, Manoel de Oliveira Dantas Filho, \\ Fernando Henrique Pereira de Vasconcelos, Armiliana Soares Nascimento, \\ Rosa Maria Mariz de Melo Sales Marmhoud Coury, Criseuda Maria Benício Barros, \\ Silvio Romero do Nascimento, Luciana de Barros Correia Fontes*
}

Rua Ester Foigel, 110, ap. 1102, Ed. Victor Rodrigues, Iputinga, Recife, Pernambuco, Brasil

Email:

Received 25 October 2013; revised 3 December 2013; accepted 21 December 2013

Copyright (c) 2013 Maria Ívina Gomes Janoca et al. This is an open access article distributed under the Creative Commons Attribution License, which permits unrestricted use, distribution, and reproduction in any medium, provided the original work is properly cited.

\begin{abstract}
The objective of this study was to evaluate the performance of oral functions and oral conditions in children and adolescents with overweight or obesity, investigating possible associations with treatment for weight reduction. Developing a cross-sectional research and quantitative approach with inductive and descriptive and critical analysis of data, such as from a range of $95 \%$, the universe was represented by children and adolescents who were overweight or obese, in both sexes, treated at reference centers for the treatment of obesity by the National Health System, in Campina Grande, Paraíba, 2010-2012. As the control group considered subjects of the same age, in the process of screening for attention in the places listed, but without the condition of overweight or obese, the research was started after the approval by the Ethics Resarch Committee of the UEPB under the protocol number 0513.0.133.000-09. As instruments for data collection were used in the questionnaire and clinical examination, of the 70 surveyed, most were female, ranging in age from 3 to 17 years, overweight, without comorbidities and carriers of deleterious oral habits; especially the nail biting, significantly associated with female sex $p<0.05$. Consistency was the preferred food paste and chewing quickly, unilaterally, without discomfort or gagging constant. There was a significant difference between the values of the DMFT index, the presence of visible biofilm and the frequency of halitosis, for groups with overweight or obesity, with association between time of treatment and medications.
\end{abstract}

${ }^{*}$ Corresponding author.
Keywords: Stomatognathic System; Oral Health; Overweight; Obesity; Comprehensive Health Care of Children and Adolescents; Pediatric Dentistry

\section{INTRODUCTION}

Obesity is a serious public health problem worldwide due to the increase in its incidence and prevalence rates, the notorious impairment of a population increasingly young (particularly juvenile) and possible implications on life quality of affected individuals and their care needs.

Brazil is passing through the nutritional transition period, where malnutrition is giving way to overweight and obesity as a nutritional disorder is most prevalent in virtually all strata of population; evidencing polarization in regions with high poverty levels, such as the northeast of the country [1].

This situation is characterized by abnormal accumulation of body fat compared with body size. Usually, the Body Mass Index or BMI $\left(\mathrm{kg} / \mathrm{m}^{2}\right)$ is overall used for the body weight assessment. This should be linked to other parameters in order to identify the risk conditions to health, particularly in children and adolescents. The levels related to the problem vary from the overweight or pre-obesity, with BMI between 25 and 29.9, obesity class I from 30 to 34.9, obesity class II from 35 to 39.9 and obesity class III, also called morbid obesity over 40 [2].

The treatment of obesity is difficult due to its multifactorial etiology resulting from the complex interaction of environmental, genetic and psychological factors, assuming different clinical situations to individuals in different socioeconomic realities. In this context, prevention 
and intervention programs need to consider the control of habits and possible behaviors, according to the cultural characteristics [3,4].

Obesity is a problem acquired throughout life, programmed in its early stage and fed over time. When in childhood and adolescence, it represents an important risk factor for the development of future co-morbidities, even with the challenge in defining its role in this causality. Thus, it becomes necessary to implement measures to combat this nutritional disorder in younger individuals [5].

Among the key policy components of a healthy life in this age group, the promotion of increased physical activity, implementation of programs of physical exercise and acquisition of healthy eating habits are highlighted [6]. In this context, the states of Pernambuco and Paraíba appear as references in attempt to control anemia and overweight/obesity, especially in the frameworks of metabolic syndrome involving children and adolescents [7].

It is known that the performance of masticatory function is directly related to body and oral or buccal variables, and the masticatory difficult being the most likely mechanism by which impaired oral health can affect food intake [8]. Associations were found between oral health and obesity: a small number of teeth, a great number of restored teeth, xerostomia, dental visiting habits and self-perceived oral health in adults [9]. However, there is little information on the oral conditions of children and adolescents with overweight or obesity and their masticatory performance when undergoing treatment for weight control.

Thus, according to what has been previously reported, this study was developed under the guiding question or problem: Is there any association between oral conditions and masticatory performance in children and adolescents with overweight and obesity before and after treatment for weight control?

\section{METHODOLOGY}

The study was cross-sectional and quantitative with inductive approach and descriptive and analytical data analysis. Its covered area included hospitals for treatment of obesity and oral health by the Unified Health System (SUS) located in Campina Grande, Paraíba State.

The universe was represented by children and adolescents overweight or obese, both sexes, attended at the Center for Endocrinology and Childhood Obesity, Health Institute Elpidio de Almeida (ISEA), through the project "Metabolic Study in Children Obese and Overweight" and the Unit of Endocrinology and Diabetes Severino Bezerra de Carvalho, University Hospital Alcides Carneiro (HUAC). Children and adolescents on the screen- ing for these services and without diagnosis of overweight or obesity were selected as control group.

The sample corresponded to 70 volunteers, aged between three and eighteen years, who sought care in the previously reported centers or under treatment, during 2010-2012. Patients with disabilities (mental, hearing, visual and physical, reporting to the motor impairment), customers or patients without accurate information on weight and height, immunocompromised individuals, and those who do not agreed on participation, even with the consent of those responsible, were excluded from the study.

No conflict of interest, the study was approved by the Research Ethics Committee (REC) of the State University of Paraíba (UEPB) under the protocol number 0513.0.133.000-09 and started after signing the Letter of Consent by the responsible regarding the investigated service and signing the informed consent by those responsible in relation to the study volunteers (in case of adolescents, also their signature). Below is the flow diagram of this study:

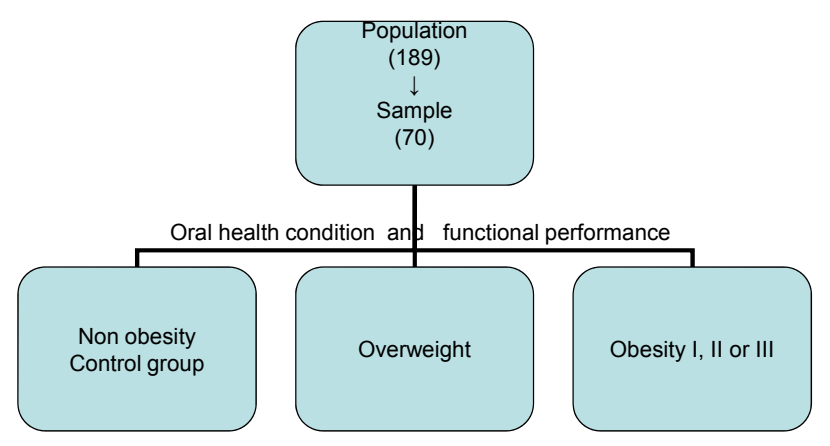

As instruments for data collection were used: face to face interview with questionnaire, intra-oral and extraoral physical examination and application of adapted masticatory assessment protocol [10]; those conducted in the Department of Dentistry UEPB, under artificial light, following the guidelines of the World Health Organization for epidemiological surveys on oral health [11] and with respect to biosafety standards. Information regarding medical history was recorded from the data in records.

The list of variables analyzed included: sex, national origin, diagnosis and degree of obesity (weight/height ratio by Body Mass Index or BMI), treatment time and modality, use of medications, weight loss, family history of obesity, presence of comorbidity, presence of deleterious oral habits, history of nervous bulimia, food preferred consistency, performance characteristics of masticatory function, presence of visible biofilm, spontaneous gums bleeding, halitosis, changes in teeth/occlusion or soft tissues, dmft and mean DMFT.

For statistical analysis were used 95\% confidence in- 
terval and tests: ANOVA, chi-square test of association, $F$ test and Pearson's correlation, using the statistical software package SPSS (Statistical Package for the Social Sciences) in its version 15 . The descriptive part considered measures of central tendency and dispersion with the relative frequencies.

\section{RESULTS}

The total sample in this study was 70 children and adolescents (37\% of universe), distributed as shown in Figure 1. The volunteers' mean age was 9.4 years (Standard Deviation or SD, 2.2 years). Females accounted for $68.6 \%$ of the volunteers.

The volunteers' mean weight was $57.4 \mathrm{Kg}$ (SD $4.2 \mathrm{~kg}$ ): the control group with $40.4 \mathrm{Kg}$ (SD $6.1 \mathrm{Kg}$ ), overweight group with $73.5 \mathrm{Kg}$ (SD $5.3 \mathrm{Kg}$ ) and obese group with 102.5 (SD $10.1 \mathrm{Kg}$ ). The highest percentage of overweight or obesity occurred in females (64.5\%). However, male volunteers showed higher degree of obesity (obesity class II). Among the eleven volunteers with such condition, 63.6\% were male.

Of the 70 children and adolescents investigated, 60 were under treatment and 10 in evaluation. For individuals who were under treatment, all had the recommendation of practicing exercise and diet control; the psychological therapy appearing in $35.7 \%$ of cases and the use of drugs in $21.4 \%$. The programs varied in time over a period of 1 month to 2 years. The maximum weight reduction occurred in $8 \mathrm{~kg}$, but in $35.7 \%$ of patients the opposite occurred with gains of up to $6 \mathrm{Kg}$ for adolescent with obesity class II.

Figure 2 shows the distribution of $58.6 \%$ of volunteers investigated who had family history of obesity. There was significant association between maternal obesity and overweight or obesity status $(p<0.05)$.

Comorbidities were mentioned for $11.4 \%$ of respondents, being high dyslipidemia (75\%), hypertension $(62.5 \%)$ and triglycerides (62.5\%) the most reported followed by diabetes (50\%).

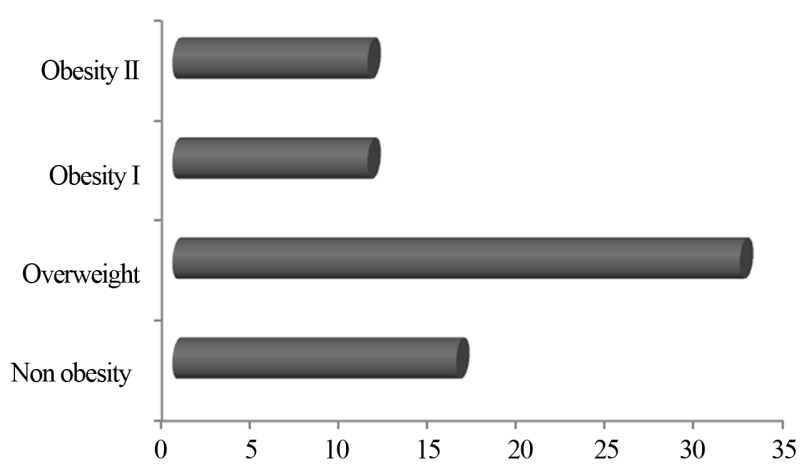

Figure 1. Graphic showing the distribution of volunteers according to diagnosis of obesity. Campina Grande, PB, 20102012.
Regarding the presence of harmful oral habits, this was confirmed to $67.1 \%$ of the sample and is shown in Figure 3. History of nervous bulimia existed for $4.3 \%$ of children and adolescents.

The Table 1 presents the masticatory pattern of volunteers. For variables analyzed there was no significant difference between the groups without obesity, overweight or obesity ( $p>0.05)$.

Regarding the oral health data, more specifically, the mean dmft was set at 2.5 and the DMFT at 3.4. For the DMFT the difference was not significant $(p>0.05)$ between the groups of volunteers with or without obesity (2.7 non-obese, 3.8 overweight, 4.3 obese class I, 4.4 obese class II). Evaluating the components DMFT separately, it could not test safely the possible associations for the first one due to a low frequency value. The component D was significantly higher in the overweight or obese group ( $p<0.05$ ), setting a $p<0.01$ when compared the non-obese and obese groups.

The presence of visible biofilm and halitosis was also more significant $(\mathrm{p}<0.05)$ in overweight or obese individuals compared to those non-obese, with relative frequencies of $14.3 \%$ and $70 \%$, respectively.

It was found spontaneous gingival bleeding in $24.3 \%$ of the sample. For other changes surveyed occurred the

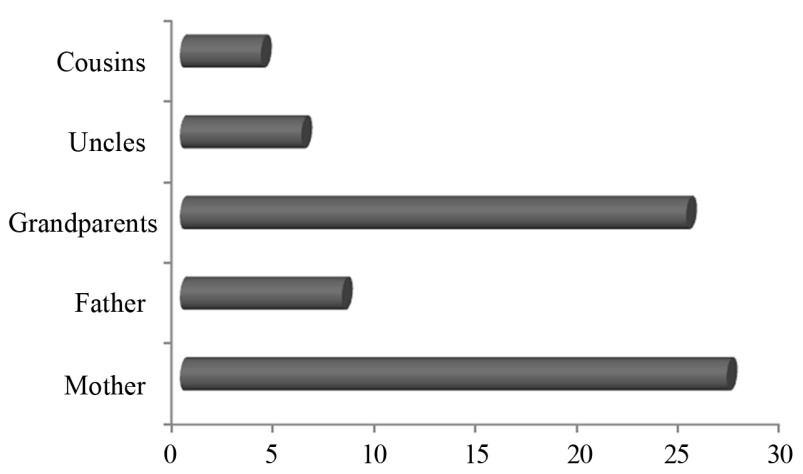

Figure 2. Graphic showing the distribution of reports of obesity in the family. Campina Grande, PB, 2010-2012.

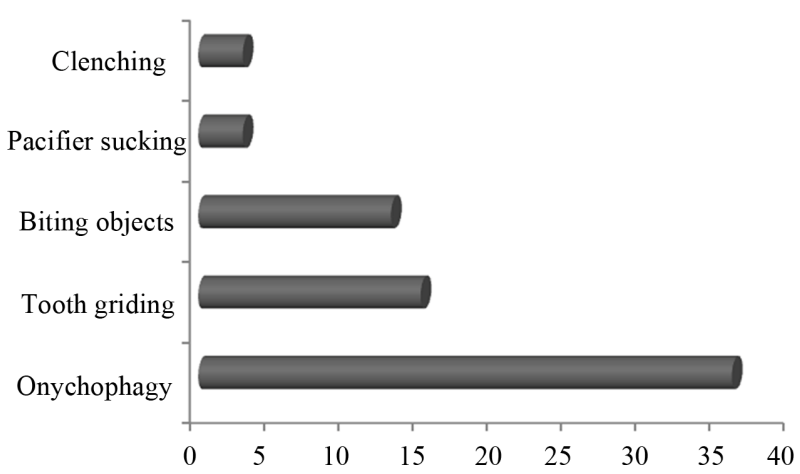

Figure 3. Graphic showing the distribution of volunteers, according to the type of deleterious oral habits presented. Campina Grande, PB, 2010-2013. 
Table 1. Chewing pattern of the volunteers. Campina Grande, PB, 2010.

\begin{tabular}{|c|c|}
\hline VARIABLES & $\mathbf{N} \%$ \\
\hline \multicolumn{2}{|c|}{ Preferred consistency of food } \\
\hline Solid & 35.7 \\
\hline Paste & 58.6 \\
\hline Liquid & 5.7 \\
\hline \multicolumn{2}{|l|}{ Side masticatory } \\
\hline Both & 45.7 \\
\hline Right & 31.4 \\
\hline Left & 22.9 \\
\hline \multicolumn{2}{|c|}{ Presence of choking } \\
\hline Yes & - \\
\hline No & 100 \\
\hline \multicolumn{2}{|c|}{ Chewing with mouth open } \\
\hline Yes & 4.3 \\
\hline No & 95.7 \\
\hline \multicolumn{2}{|l|}{ Chewing speed } \\
\hline Slow & 31.4 \\
\hline Regular/normal & 22.9 \\
\hline Fast & 45.7 \\
\hline \multicolumn{2}{|l|}{ Pain when chewing } \\
\hline Yes & 8.6 \\
\hline No & 91.4 \\
\hline \multicolumn{2}{|c|}{ Difficult to open or close the mouth } \\
\hline Yes & 4.3 \\
\hline No & 95.7 \\
\hline
\end{tabular}

percentage distribution following also not proved statistically significant, yielding global values of $22.9 \%$ of patients with open bite or dental crowding (each one), $14.3 \%$ with wear on tooth surface or sharp spacing between teeth, $11.4 \%$ with crossbite bite or tooth fracture, $5.7 \%$ with sharp anomaly or overbite/deep overbite.

The significant parameters for oral health conditions and masticatory performance between groups were evaluated according to the Table 1. Those obtained from prior correlation with all variables investigated.

\section{DISCUSSION}

The higher frequency of females associated with obesity was also highlighted in the studies of Lima and Sampaio [12] and Marscicano [13]; those with percentages higher than $74 \%$ and $72 \%$, respectively. A systematic literature review conducted by Berghofer et al. [14] corroborated the works consulted when finding higher prevalence of obesity in women.

Promoting changing conditions to healthy habits for nutrition and physical exercise among children and adolescents is no simple task. We agree with Vignolo et al. [15], when they mention the value of a multidisciplinary team and family participation in programs aimed at weight loss and gain in life quality. It should seek to understand the individual and environmental factors that may be determinant of these changes, which requires time. To the aforementioned authors, five years of follow-up, in the present study a maximum of two years.

The satisfaction with activities in the program for weight reduction, where access organization and educational content are key elements, were not measured. However, organizational content, according to Kitscha et al. [16], included the nutritional re-education, physical activity, necessary interventions (medication and psychotherapy), guidelines for participants and their parents or guardians (taking into account the family history of obesity).

From a psychological standpoint, there is a need for special attention to obese individuals, particularly children and adolescents, due to common problems to acceptance in the school (with bulling cases) or family environments and self-esteem, with low possibility of developing leadership attitudes, reduced cycle of friendships and prone to more aggressive behaviors directed at their self-image or identity [17].

Oliveira et al. [18] demonstrated association between family history of obesity and a high BMI, especially with maternal obesity; a fact confirmed in this study ( $p<0.05$ in both overweight and obesity).

The associated comorbidities are in agreement with the study of Franca and Alves [19]. These authors suggested early prevention of obesity and cardiovascular diseases as a priority in public health programs.

The relationship between changes in nutrition worldwide with increased overweight and obesity on the oral health status has been highlighted [20]. However, information gaps exist regarding the functional performance of the stomatognathic system, particularly the orofacial motricity, making it difficult to compare the data obtained in this study with other studies in the literature.

Regarding the presence of deleterious oral habits, this was confirmed for $67.1 \%$ of the sample being shown in Figure 3. It is noteworthy that most of the observed habits is directed to the performance of the mastication and beyond the significant emotional factor, there may be a compensatory way.

History of nervous bulimia existed for $4.3 \%$ of children and adolescents. For Peterson et al. [21], this disor- 
der would be directly related to high levels of stress and depression in patients with eating disorders and would need to be computed so odd to conduct the treatment and control of these individuals when losing weight.

Chewing has implications for activation of histamine neurons (HA), those responsible for the increased lipolysis in adipose tissues and the feeling of fullness or satiety [22]. However, little is surveyed on the influence of mastication in the process of weight reduction. Apolinário, Moraes and Motta [23] in the study involving the masticatory evaluation of 30 patients on the diet, reported that the guidelines on chewing are made in most of guidelines with emphasis on the speed and number of chewing cycles. They added that there is adaptation of the masticatory process, despite the unilateral mastication having been much noted. In this study, besides one preferred side, there was a preferred food consistency and speed masticatory unfavorable to the process; however, with no significant differences between overweight/obese group and that one without this condition.

When reporting to oral conditions themselves, Bailleul-Forestier et al., [24] identified a higher DMFT in obese patients (mean 6.9) compared to those non-obese (4.3); superior results to those found in this study.

The inadequate food habits associated with frequency of food intake and low self-esteem (which includes care with personal hygiene) can be considered a risk factor for periodontal diseases by favoring the formation and calcification of the dental biofilm.

Genco et al., [25] found significant association between BMI and periodontal disease in obese individuals. These authors mentioned insulin resistance as a mediator of this relationship, without highlighting the occlusal aspects. The malocclusions observed in this study also possessed no significant association with BMI of volunteers.

The clinical implications of this study point to a different approach for the planning of Dental Caries Preventive Programs in children and adolescents obese or overweight.

A Different Approach for the Planning of Dental Caries Preventive Programs.

\section{CONCLUSION}

Based on the results, a longer treatment with medication was directly associated with oral conditions in children and adolescents overweight or obese, particularly with the higher DMFT rates, presence of visible biofilm and higher frequency of halitosis.

\section{REFERENCES}

[1] Silva, J.B., Silva, F.G., Medeiros, H.J., Roncalli, A.G. and Knackfuss, M.I. (2009) Estado nutricional de lós
Estudiantes de la región semiárida Del noreste de Brasil. Revista de Salud Publica (Bogota), 11, 62-71. http://dx.doi.org/10.1590/S0124-00642009000100007

[2] El Taguri, A., Dabbas-Tyan, M., Goulet, O. and Ricour, C. (2009) The use of body mass index for measurement of fat mass in children is highly dependant on abdominal fat. WHO, Eastern Mediterranean Health Journal, 15, 563-573.

[3] Arora. A., Scott, J.A., Bhole, S., Do, L., Schwarz, E. and Blinkhorn, A.S. (2011) Early childhood feeding practices and dental caries in preschool children: A multi-centre birth cohort study. BMC Public Health, 11, 28. http://dx.doi.org/10.1186/1471-2458-11-28

[4] Silva-Sanigorski, A.M., Waters, E., Calache, H., Smith, M., Gold, L., Gussy, M., Scott, A., Lacy, K. and VirgoMilton, M. (2011) Splash!: A prospective birth cohort study of the impact of environmental social and familylevel influences on child oral health and obesity related risk factors and outcomes. BMC Public Health, 11, 505.http://dx.doi.org/10.1186/1471-2458-11-505

[5] Monteiro, P., Victora, C. and Barros, F. (2004) Fatores de risco sociais, familiares e comportamentais para obesidade em adolescentes. Revista Panamericana de Salud Publica, 16, 250-258.

http://dx.doi.org/10.1590/S1020-49892004001000004

[6] Oliveira, C.L., Mello, M.T., Cintra, I.S. and Mauro, F.M. (2004) Obesidade e síndrome metabólica na infância e adolescência. Revista de Nutrição, 17, 237-245. http://dx.doi.org/10.1590/S1415-52732004000200010

[7] Batista Filho, M., Souza, A.I., Miglioli, T.C. and Santos, M.C. (2008) Anemia e obesidade: Um paradoxo da transição nutricional brasileira. Cadernos de Saúde Pública, 24, S247-S257.

http://dx.doi.org/10.1590/S0102-311X2008001400010

[8] Touger-Decker, R. and Mobley, C.C. (American Dietetic Association) (2007) Position of the American dietetic association. Oral. Journal of the American Dietetic Association, 107, 1418-1428. http://dx.doi.org/10.1016/j.jada.2007.06.003

[9] Östberg, A.L., Bengtsson, C., Lissner, L. and Hakeberg, M. (2012) Oral health and obesity indicators. BMC Oral Health, 12, 50. http://dx.doi.org/10.1186/1472-6831-12-50

[10] Genaro, K.F., Berretin-Félix, G., Rehder, M.I.B.C. and Marchesan, I.Q. (2009) Avaliação miofuncional orofacial -Protocolo MGBR. Revista Cefac, 237-255.

[11] Oliveira, A.J.R.C., Unfer, B., Costa, I.C.C., Arcieri, R.M., Guimarães, L.O.C. and Saliba, N.A. (1998) Levantamentos epidemiológicos em saúde bucal: análise da metodologia proposta pela Organização Mundial de Saúde. Revista Brasileira de Epidemiologia, 1, 177-189. http://dx.doi.org/10.1590/S1415-790X1998000200008

[12] Lima, L.P.D. and Sampaio, H.A.D.C. (2007) Caracterização socioeconômica, antropométrica e alimentar de obesos graves. Ciências e Saúde Coletiva, 12, 1011-1020. http://dx.doi.org/10.1590/S1413-81232007000400022

[13] Marsicano, J.A. (2008) Avaliação das condições bucais de pacientes obesos e de submetidos à cirurgia bariátrica [dissertação de mestrado]. Faculdade de Odontologia da 
Universidade de São Paulo, Bauru.

[14] Berghöfer, A., Pischon, T., Reinhold, T., Apovian, C.M., Sharma, A.M. and Willich, S.N. (2008) Obesity prevalence from a European perspective: A systematic review. BMC Public Health, 8, 200. http://dx.doi.org/10.1186/1471-2458-8-200

[15] Vignolo, M., Rossi, F., Bardazza, G., Pistorio, A., Parodi, A., Spigno, S., Torrisi, C., Gremmo, M,. Veneselli, E. and Aicardi, G. (2008) Five-year follow-up of a cognitive-behavioural lifestyle multidisciplinary programme for childhood obesity outpatient treatment. Europen Journal of Clinical Nutrition, 62, 1047-1057. http://dx.doi.org/10.1038/sj.ejcn.1602819

[16] Kitscha, C.E., Brunet, K., Farmer, A. and Mager, D.R. (2009) Reasons for non-return to a pediatric weight management program. Canadian Journal of Diet Practices and Research, 70, 89-94.

http://dx.doi.org/10.3148/70.2.2009.89

[17] Zeller, M.H., Reiter-Purtill, J. and Ramey, C. (2008) Negative peer perceptions of obese children in the classroom environment. Obesity, 16, 755-762. http://dx.doi.org/10.1038/oby.2008.4

[18] Oliveira, L.P.M., Assis, A.M.O., Silva, M.C.M., Santana, M.L.P., Santos, N.A., Pinheiro, S.M.C., Barreto, M.L. and Souza, C.O. (2009) Fatores associados a excesso de peso e concentração de gordura abdominal em adultos na cidade de Salvador, Cadernos de Saúde Publica, Bahia, 25, 570-582. http://dx.doi.org/10.1590/S0102-311X2009000300012

[19] Franca, E. and Alves, J.G.B. (2006) Dislipidemia entre crianças e adolescentes de Pernambuco. Arquivos Brasileiros de Cardiologia, 87, 722-727. http://dx.doi.org/10.1590/S0066-782X2006001900007

[20] Enwonwu, C.O. (2010) Global nutrition transition challenges oral health. Compendium of Continuing Education in Dentistry, 31, 98-99.

[21] Peterson, C.B., Thuras, P., Ackard, D.M., Mitchell, J.E., Berg, K., Sandager, N. and Wonderlich, S.A. (2010) Personality dimensions in bulimia nervosa, binge eating disorder, and obesity. Comprehensive Psychiatry, 51, 31-36. http://dx.doi.org/10.1016/j.comppsych.2009.03.003

[22] Sakata, T., Yoshimatsu, H., Masaki, T. and Tsuda, K. (2003) Anti-obesity actions of mastication driven by histamine neurons in rats. Experimental Biology and Medicine, 228, 1106-1110.

[23] Apolinário, R.M.C., Moraes, R.B. and Motta, A.R. (2008) Mastigação e dietas alimentares para a redução do peso. Revista Cefac, 10, 191-199. http://dx.doi.org/10.1590/S1516-18462008000200008

[24] Bailleul-Forestier, I., Lopes, K., Sounames, M., Azouguy-Levy, S. and Frelut, M.L. (2007) Caries experience in a severely obese adolescent population. Journal of the International Association of Dentistry for Children, 17, 358-363.

[25] Genco, R.J., Grossi, S.G., Ho, A., Nishimura, F. and Murayama, Y.A. (2005) A proposed mode linking inflammation to obesity, diabetes, and periodontal infections. Journal of Periodontology, 76, 2075-2084. http://dx.doi.org/10.1902/jop.2005.76.11-S.2075 